\title{
Corticosteroid Responsiveness in Patients With Acute Exacerbation of Interstitial Lung Disease Admitted to the Emergency Department
}

Hye Jin Jang

Yonsei University

Seung Hyun Yong

Yonsei University

Ah Young Leem

Yonsei University

Su Hwan Lee

Yonsei University

Song Yee Kim

Yonsei University

Sang Hoon Lee

Yonsei University

Eun Young Kim

Yonsei University

Kyung Soo Chung

Yonsei University

Ji Ye Jung

Yonsei University

Young Ae Kang

Yonsei University

Young Sam Kim

Yonsei University

Joon Chang

Yonsei University

Moo Suk Park ( pms70@yuhs.ac)

Yonsei University

Research Article

Keywords: ILD, IPF, AE-ILD, Corticosteroids 
Posted Date: December 7th, 2020

DOl: https://doi.org/10.21203/rs.3.rs-110787/v1

License: (c) (i) This work is licensed under a Creative Commons Attribution 4.0 International License. Read Full License

Version of Record: A version of this preprint was published at Scientific Reports on March 11th, 2021. See the published version at https://doi.org/10.1038/s41598-021-85539-1. 


\section{Abstract}

Interstitial lung disease (ILD), particularly idiopathic pulmonary fibrosis (IPF), has a poor prognosis. Corticosteroids are widely used in the treatment of acute exacerbation of ILD (AE-ILD). This study aimed to clarify the causes of AE-ILD, determine the efficacy of corticosteroids for treating AE-ILD, and detect differences in the mortality rate among subgroups of ILD. This was an observational retrospective singlecenter study. Patients with ILD who presented to the emergency department with acute respiratory symptoms from January 1, 2016, to December 31, 2018, were included. Patients with AE-ILD were classified into two groups depending on the prednisolone dose: low dose (0 to $1.0 \mathrm{mg} / \mathrm{kg}$ ) or high dose $(>1.0 \mathrm{mg} / \mathrm{kg})$. Mortality rates between patients with and without IPF were compared.

This study included 182 patients with AE-ILD, including IPF $(n=117)$ and non-IPF $(n=65)$. Multivariate Cox regression analysis showed that corticosteroid dose (HR:0.221, Cl:0.102-0.408, $P<0.001$ ), initial P/F ratio (HR:0.995, Cl:0.992-0.999, $P=0.006$ ), and mechanical ventilation within 3 days of hospitalization (HR:4.205, Cl:2.059-8.589, $P<0.001$ ) were independent risk factors for mortality in patients with AE-ILD.

This study showed that outcomes improve with higher doses of corticosteroids ( $>1 \mathrm{mg} / \mathrm{kg}$ prednisolone) in patients with AE-non-IPF-ILD. However, this was not the case in patients with AE-IPF.

\section{Introduction}

Interstitial lung disease (ILD) is a diffuse parenchymal lung disease characterized by inflammation and/or fibrosis of the interstitium, alveoli, and/or terminal bronchioles, with etiologies ranging from rheumatologic or environmental to idiopathic ${ }^{1}$. It has been estimated that approximately 100,000 hospital admissions per year and $15 \%$ of all pulmonologist appointments are due to ILD ${ }^{2}$. The common feature across different ILD types, irrespective of the clinical presentation, disease progression, or prognosis, is fibrotic destruction of the lung parenchyma ${ }^{3}$. An acute exacerbation of ILD (AE-ILD) can occur at any time, and is associated with significant morbidity and mortality.

Idiopathic pulmonary fibrosis (IPF) is the most severe form of ILD. Acute exacerbation of IPF (AE-IPF) portends an even worse prognosis, with earlier studies reporting a mortality of $50-80 \%$ and a median survival time of 3-4 months ${ }^{4,5}$. However, more recent studies have suggested slightly higher survival rates: 1 -month survival rate of $66 \%$ (range: $47-85 \%$ ); 3 -month survival rate of $41 \%$ (range: $0-54 \%$ ); and survival to hospital discharge of $44 \%(4-77 \%)^{6}$. A study conducted in Japan has even reported survival rates of over $70 \%$ in patients treated with cyclosporin A or high-dose corticosteroids ${ }^{7}$. Approximately $20 \%$ of patients with IPF will experience AE-IPF over the course of their disease, and about one-fifth of these patients will have more than one AE-IPF episode ${ }^{4-6}$; thus, $A E$ is now recognized as a relatively common event ${ }^{7}$. Although $A E$ has been mainly described in patients with IPF, the presentation and consequences of AE appear to be similar in other ILDs. While there is no cohesive definition of AE for ILDs other than IPF, criteria similar to those of AE-IPF are often used ${ }^{1}$. Additionally, AE-ILD has been associated with decreased survival in patients with any connective tissue disease-related ILD ${ }^{8}$. Although AE-IPF is being 
increasingly recognized and perceived as a severe event with high associated mortality, there is only a limited amount of clinical data on AE-ILD in non-IPF ILD ${ }^{9}$. Some studies have attempted to identify risk factors common to all forms of AE-ILD; however, their results have often been inconsistent ${ }^{1}$. In IPF, low forced vital capacity (FVC), low total lung capacity, decreased 6-minute walk distance, pulmonary hypertension, baseline hypoxemia, low diffusing capacity of the lung for carbon monoxide $\left(\mathrm{DL}_{\mathrm{co}}\right)$, increased dyspnea, and no history of smoking are all associated with an increased risk of exacerbation ${ }^{10,11}$. Nevertheless, previous sufficient case series have failed to confirm these associations.

High-dose corticosteroids, sometimes administered as pulse therapy (with or without immunosuppressive agents) in combination with broad-spectrum antimicrobial agents, have been used most commonly in patients with AE-ILD. This is the recommended treatment according to recent international treatment guidelines for IPF ${ }^{12}$. However, the efficacy of this therapy is uncertain, and survival is still very low ${ }^{4}$.

The aim of this study was to clarify the causes of AE-ILD and the risk factors associated with mortality, particularly corticosteroid responsiveness, in patients with AE-ILD admitted to the emergency department (ED).

\section{Results}

\section{Patient characteristics and microbiology}

A total of 182 patients were included in the study, and the baseline characteristics of the study sample are shown in Table 1. The mean patient age was $68.7 \pm 11.6$ years. Among the total patients, $117(64.3 \%)$ had IPF, $67.0 \%$ were male, and $45.4 \%$ had a history of smoking. Patients in the IPF group were more commonly exposed to smoking (57.9\%) than those in the non-IPF ILD group (21.7\%). FVC and forced expiratory volume in the first second $\left(\mathrm{FEV}_{1}\right)$ were significantly higher in the non-IPF ILD group compared to the IPF group.

The mean dose of prednisolone was $1.0 \mathrm{mg} / \mathrm{kg}$ in the IPF group and $1.1 \mathrm{mg} / \mathrm{kg}$ in the non-IPF ILD group. The total mortality was 40 cases (22.0\%), with 30 cases (25.6\%) in the IPF group and 10 cases $(15.4 \%)$ in the non-IPF group. 
Table 1

Baseline characteristics of patients with acute exacerbation of IPF and non-IPF ILD

\begin{tabular}{|c|c|c|c|c|}
\hline Variable & Total & IPF & Non-IPF & $\begin{array}{l}P \\
\text { value }\end{array}$ \\
\hline Total patients & 182 & 117 & 65 & \\
\hline Age, years & $68.7 \pm 11.6$ & $69.4 \pm 9.9$ & $67.4 \pm 14.1$ & 0.27 \\
\hline Sex, men & $122(67.0)$ & $94(80.3)$ & $28(43.1)$ & $\begin{array}{l}<.001 \\
0.001\end{array}$ \\
\hline \multicolumn{5}{|l|}{ Smoking exposure, n (\%) } \\
\hline Never & $95(54.6)$ & $48(42.1)$ & 47 (78.3) & $\begin{array}{l}< \\
0.001\end{array}$ \\
\hline Former & $77(44.3)$ & $64(56.1)$ & $13(21.7)$ & \\
\hline Current & $2(1.1)$ & $2(1.8)$ & $0(0.0)$ & \\
\hline Pack-years & $35.0(20.0-48.5)$ & $35.0(20.0-50.0)$ & $25.0(20.0-40.0)$ & 0.09 \\
\hline FVC \% predicted & $60.0(46.0-74.0)$ & $57.0(41.0-69.0)$ & $67.0(55.0-80.0)$ & 0.003 \\
\hline $\mathrm{FEV}_{1} \%$ predicted & $71.0(56.0-85.0)$ & $67.0(50.5-80.0)$ & $75.5(61.0-92.0)$ & 0.02 \\
\hline $\mathrm{DL}_{\mathrm{co}}$ \% predicted & $47.0(35.0-59.0)$ & $44.0(31.0-60.0)$ & $49.0(37.3-58.0)$ & 0.11 \\
\hline Initial $P / F$ ratio & $\begin{array}{l}223.4(158.0- \\
310.0)\end{array}$ & $\begin{array}{l}220.0(148.0- \\
291.7)\end{array}$ & $\begin{array}{l}233.9(179.6- \\
339.3)\end{array}$ & 0.29 \\
\hline GAP score & $4(4.0,6.0)$ & $4(3.0,4.0)$ & $4(3.75,5.0)$ & 0.16 \\
\hline Prednisolone $(\mathrm{mg} / \mathrm{kg})$ & $1.0 \pm 0.9$ & $1.0 \pm 0.8$ & $1.1 \pm 0.9$ & 0.20 \\
\hline Previous AE history & $60(33.0)$ & $43(36.8)$ & $17(26.2)$ & 0.20 \\
\hline Anti-fibrotics & $54(29.7)$ & $54(46.2)$ & $0(0.0)$ & $\begin{array}{l}< \\
0.001\end{array}$ \\
\hline Supplemental $\mathrm{O}_{2}$ & $37(20.3)$ & $28(23.9)$ & $9(13.8)$ & 0.19 \\
\hline Prednisolone before $\mathrm{AE}$ & $91(50.0)$ & $49(41.9)$ & $42(64.6)$ & 0.97 \\
\hline \multicolumn{5}{|l|}{ Medical history, n (\%) } \\
\hline \multicolumn{5}{|l|}{ Abbreviations: } \\
\hline \multicolumn{5}{|c|}{ 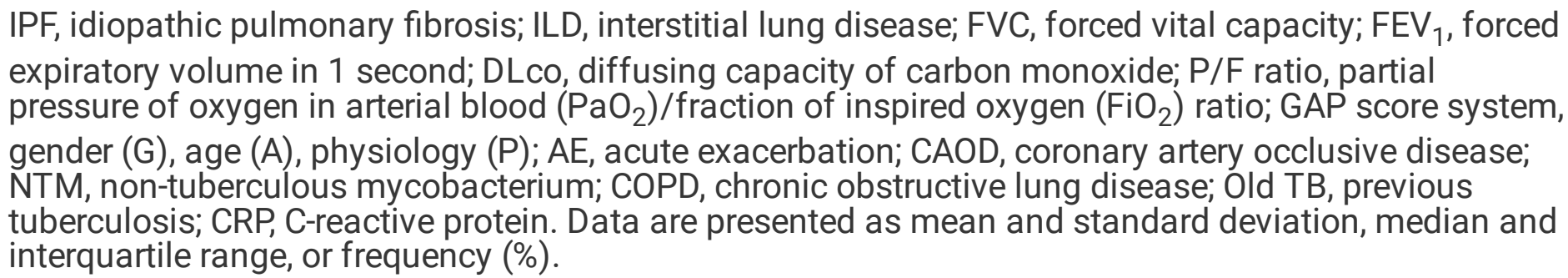 } \\
\hline
\end{tabular}




\begin{tabular}{|c|c|c|c|c|}
\hline Variable & Total & IPF & Non-IPF & $\begin{array}{l}P \\
\text { value }\end{array}$ \\
\hline Hypertension & 33 (18.1) & $25(21.4)$ & 8 (12.3) & 0.13 \\
\hline Diabetes mellitus & $32(17.6)$ & $24(20.5)$ & 8 (12.3) & 0.16 \\
\hline CAOD & $19(10.4)$ & $13(11.1)$ & $6(9.2)$ & 0.69 \\
\hline NTM & $7(3.8)$ & $4(3.4)$ & $3(4.6)$ & 0.69 \\
\hline Old TB & $11(6.0)$ & $8(6.8)$ & $3(4.6)$ & 0.55 \\
\hline COPD & $12(6.6)$ & $6(5.1)$ & $6(9.2)$ & 0.29 \\
\hline Malignancy & $36(19.8)$ & $21(17.9)$ & $15(23.1)$ & 0.41 \\
\hline $\begin{array}{l}\text { Use of vasopressors within } 3 \\
\text { days }\end{array}$ & $26(14.3)$ & $19(16.2)$ & $7(10.8)$ & 0.31 \\
\hline $\begin{array}{l}\text { Need for mechanical } \\
\text { ventilator }\end{array}$ & 35 (19.2) & $24(20.5)$ & $11(16.9)$ & 0.56 \\
\hline CRP (mg/L) & $70.5(21.0-140.0)$ & $65.0(21.0-136.0)$ & $78.0(27.0-140.0)$ & 0.33 \\
\hline 90 day-mortality & $40(22.0)$ & $30(25.6)$ & $10(15.4)$ & 0.21 \\
\hline \multicolumn{5}{|l|}{ Abbreviations: } \\
\hline \multicolumn{5}{|c|}{$\begin{array}{l}\text { IPF, idiopathic pulmonary fibrosis; ILD, interstitial lung disease; } F V C \text {, forced vital capacity; } F E V_{1} \text {, forced } \\
\text { expiratory volume in } 1 \text { second; } \mathrm{DLCO} \text {, diffusing capacity of carbon monoxide; } \mathrm{P} / \mathrm{F} \text { ratio, partial } \\
\text { pressure of oxygen in arterial blood }\left(\mathrm{PaO}_{2}\right) / \text { fraction of inspired oxygen }\left(\mathrm{FiO}_{2}\right) \text { ratio; GAP score system, } \\
\text { gender }(\mathrm{G}) \text {, age }(\mathrm{A}) \text {, physiology }(\mathrm{P}) ; \mathrm{AE}, \text { acute exacerbation; } \mathrm{CAOD} \text {, coronary artery occlusive disease; } \\
\text { NTM, non-tuberculous mycobacterium; COPD, chronic obstructive lung disease; Old TB, previous } \\
\text { tuberculosis; CRP, C-reactive protein. Data are presented as mean and standard deviation, median and } \\
\text { interquartile range, or frequency }(\%) \text {. }\end{array}$} \\
\hline
\end{tabular}

Table 2 shows the comparison between the triggered AE-ILD and non-triggered AE-ILD groups. The triggered AE-ILD group had lower $\mathrm{P} / \mathrm{F}$ ratios and higher prednisolone doses and lactate levels. The mortality was 11 cases (22\%) in the triggered group and 12 cases $(15.8 \%)$ in the non-triggered group; however, the difference was not statistically significant $(P=0.377)$. 
Table 2

Comparison of baseline characteristics between triggered and non-triggered AE-ILD groups

\begin{tabular}{|c|c|c|c|}
\hline Variable & Triggered group & Non-triggered group & $P$-value \\
\hline Total patients, $n$ & 50 & 81 & \\
\hline Age, years & $71.5(60.8,77.0)$ & $72(64.0,78.0)$ & 0.271 \\
\hline Sex, male & $34(68)$ & $45(55.6)$ & 0.318 \\
\hline IPF & $31(62)$ & $42(51.9)$ & 0.454 \\
\hline Initial $P / F$ ratio & $217.2(160.3,285.8)$ & $253.6(188.7,400.0)$ & 0.017 \\
\hline FVC (\%), predicted & $60(47.0,73.0)$ & $62.0(51.5,78.5)$ & 0.623 \\
\hline DLco (\%), predicted & $50.0(33.3,66.8)$ & $49.0(36.8,58.3)$ & 0.749 \\
\hline Prednisolone (mg/kg) & $1.1(0.5,1.5)$ & $0.6(0.2,1.2)$ & 0.011 \\
\hline $\mathrm{CRP}(\mathrm{mg} / \mathrm{L})$ & $68.5(28.5,145.5)$ & $78.5(28.4,159.8)$ & 0.437 \\
\hline Lactate (mmol/L) & $1.6(1.3,2.7)$ & $1.4(1.0,1.9)$ & 0.024 \\
\hline Use of vasopressors within 3 days & $7(14)$ & 15 (19.7) & 0.407 \\
\hline Need for mechanical ventilator & $11(22)$ & $24(29.6)$ & 0.402 \\
\hline 90-day mortality & $11(22)$ & $12(15.8)$ & 0.377 \\
\hline \multicolumn{4}{|c|}{$\begin{array}{l}\text { Abbreviations: IPF, idiopathic pulmonary fibrosis; } \mathrm{AE}-\mathrm{ILD} \text {, acute exacerbation of interstitial lung } \\
\text { disease; FVC, forced vital capacity; } \mathrm{DLCO} \text {, diffusing capacity of carbon monoxide; } \mathrm{P} / \mathrm{F} \text { ratio, partial } \\
\text { pressure of oxygen in arterial blood }\left(\mathrm{PaO}_{2}\right) / \text { fraction of inspired oxygen }\left(\mathrm{FiO}_{2}\right) \text { ratio; } \mathrm{CRP} \text {, } \mathrm{C} \text {-reactive } \\
\text { protein. Data are presented as mean and standard deviation, median and interquartile range, or } \\
\text { frequency }(\%) \text {. }\end{array}$} \\
\hline
\end{tabular}

Table 3 shows the microbiologic analysis of the triggered AE-ILD group. Bacterial infection was dominant in both IPF (23.4\%) and non-IPF (15.2\%) ILD groups. Viral infection was the second most common trigger in the IPF group, while fungal infection (e.g. Pneumocystis jiroveci pneumonia) was the second most common trigger in the non-IPF ILD group (13.5\%). 
Table 3

Microbiologic results in the triggered AE-ILD group

\begin{tabular}{|llll|}
\hline Microbiology, $\boldsymbol{n}$ & Total $(\mathbf{n}=\mathbf{1 3 1})$ & IPF $(\mathbf{n}=\mathbf{7 4})$ & Non-IPF ILD $(\mathbf{n}=\mathbf{5 7})$ \\
\hline Negative results, \% & $81(61.8)$ & $46(62.2)$ & $35(61.4)$ \\
\hline Bacterial infection, \% & $28(21.4)$ & $18(24.3)$ & $10(17.5)$ \\
\hline Pseudomonas aeruginosa & $7(5.3)$ & $5(6.8)$ & $2(3.5)$ \\
\hline Mycoplasma & $6(4.6)$ & $5(6.8)$ & $1(1.8)$ \\
\hline Legionella & $6(4.6)$ & $4(5.4)$ & $2(3.5)$ \\
\hline Klebsiella pneumoniae & $5(3.8)$ & $2(2.7)$ & $3(5.4)$ \\
\hline Stenotrophomonas maltophilia & $1(0.7)$ & $1(1.4)$ & $0(0)$ \\
\hline Streptococcus pneumoniae & $1(0.7)$ & $1(1.4)$ & $0(0)$ \\
\hline Acinetobacter baumannii & $1(0.7)$ & $0(0)$ & $1(1.8)$ \\
\hline Serratia marcescens & $1(0.7)$ & $0(0)$ & $1(1.8)$ \\
\hline Viral infection*, \% & $10(7.0)$ & $7(9.5)$ & $3(5.4)$ \\
\hline Fungal infection, \% & $12(9.2)$ & $3(4.2)$ & $9(15.8)$ \\
\hline Pneumocystis jiroveci & $11(8.4)$ & $2(2.7)$ & $9(15.8)$ \\
\hline Aspergillus & $1(0.7)$ & $1(1.4)$ & $0(0)$ \\
\hline * Metapneumovirus, Influenza virus, Coronavirus, Rhinovirus, and RSV; AE-ILD, acute exacerbation of \\
interstitial lung disease
\end{tabular}

\section{Survival Outcomes}

Table 4 shows the comparison of characteristics between survivors and non-survivors. Forty $(22 \%)$ patients out of 182 died within 90 days, and most were male (70\%). The non-survivor group showed a trend of lower $\mathrm{FEV}_{1}, \mathrm{DLCO}$, and $\mathrm{P} / \mathrm{F}$ ratio. Prednisolone was prescribed at a higher dose in the survivor group $(1.1 \pm 0.9)$ than in the non-survivor group $(0.9 \pm 0.6)$, but this was not statistically significant. The rate of mechanical ventilation was more than three-fold higher in the non-survivor group $(42.5 \%)$ than in the survivor group (12.7\%), and this was statistically significant. The use of vasopressors in the first 3 hospitalization days was higher in the non-survivor group (22.5\% compared to $12.0 \%$ in the survivor group). Comparisons between survivors and non-survivors within the IPF group (e-Table 1 ) and within the non-IPF group (e-Table 2) yielded equivalent results. 
Table 4

Comparison of characteristics between survivors and non-survivors in patients with acute exacerbation of ILD.

\begin{tabular}{|c|c|c|c|c|}
\hline Variable & Total & Survivors & Non-survivors & $\begin{array}{l}P \\
\text { value }\end{array}$ \\
\hline Total patients & 182 & $142(78.0)$ & $40(22.0)$ & \\
\hline Age, years & $68.7 \pm 11.6$ & $69.0 \pm 11.7$ & $67.6 \pm 11.5$ & 0.52 \\
\hline Sex, men & $122(67.0)$ & $94(66.2)$ & $28(70.0)$ & 0.65 \\
\hline \multicolumn{5}{|c|}{ Smoking exposure, No. (\%) } \\
\hline Never & $95(54.6)$ & $72(53.3)$ & $23(59.0)$ & 0.65 \\
\hline Former & $77(44.3)$ & $61(45.2)$ & $16(41.0)$ & \\
\hline Current & $2(1.1)$ & $2(1.5)$ & $0(0.0)$ & \\
\hline Pack-years & $35.0(20.0-48.5)$ & $35.0(20.0-50.0)$ & $35.0(18.0-40.0)$ & 0.38 \\
\hline FVC \% predicted & $60.0(46.0-74.0)$ & $60.0(47.0-75.0)$ & $60.0(45.0-70.0)$ & 0.52 \\
\hline $\mathrm{FEV}_{1} \%$ predicted & $71.0(56.0-85.0)$ & $72.0(56.0-85.0)$ & $68.0(52.0-80.0)$ & 0.43 \\
\hline $\mathrm{DL}_{\mathrm{CO}}, \%$ predicted & $47.0(35.0-59.0)$ & $49.0(37.0-61.5)$ & $36.5(29.5-54.0)$ & 0.14 \\
\hline Initial P/F ratio & $\begin{array}{l}223.4(158.0- \\
310.0)\end{array}$ & $\begin{array}{l}236.4(158.9- \\
316.7)\end{array}$ & $\begin{array}{l}210.5(149.6- \\
279.0)\end{array}$ & 0.32 \\
\hline GAP score & $4(4.0,6.0)$ & $4(3.75,5.0)$ & $4(3.0,4.0)$ & 0.16 \\
\hline Prednisolone $(\mathrm{mg} / \mathrm{kg})$ & $1.0 \pm 0.9$ & $1.1 \pm 0.9$ & $0.9 \pm 0.6$ & 0.45 \\
\hline Previous AE history & $60(33.0)$ & $48(33.8)$ & $12(30.0)$ & 0.59 \\
\hline Anti-fibrotics & $54(29.7)$ & $46(32.4)$ & $8(20.0)$ & 0.87 \\
\hline Supplemental $\mathrm{O}_{2}$ & $37(20.3)$ & $29(20.4)$ & $8(20.0)$ & 0.29 \\
\hline Prednisolone before $\mathrm{AE}$ & $91(50.0)$ & $73(51.4)$ & $18(45.0)$ & 0.29 \\
\hline \multicolumn{5}{|l|}{ Medical history, n (\%) } \\
\hline Hypertension & $33(18.1)$ & $23(16.2)$ & $10(25.0)$ & 0.20 \\
\hline Diabetes mellitus & 32 (17.6) & $27(19.0)$ & $5(12.5)$ & 0.34 \\
\hline \multicolumn{5}{|c|}{$\begin{array}{l}\text { Abbreviations: ILD, interstitial lung disease; } F V C \text {, forced vital capacity; } F E V_{1} \text {, forced expiratory volume } \\
\text { in } 1 \text { second; } \mathrm{DLCO} \text {, diffusing capacity of carbon monoxide; } \mathrm{P} / \mathrm{F} \text { ratio, partial pressure of oxygen in } \\
\text { arterial blood }\left(\mathrm{PaO}_{2}\right) \text { /fraction of inspired oxygen }\left(\mathrm{FiO}_{2}\right) \text { ratio; } \mathrm{GAP} \text { score system, gender }(\mathrm{G}) \text {, age }(\mathrm{A}) \text {, } \\
\text { physiology }(\mathrm{P}) ; \mathrm{AE} \text {, acute exacerbation; } \mathrm{CAOD} \text {, coronary artery occlusive disease; IPF, idiopathic } \\
\text { pulmonary fibrosis; NTM, non-tuberculous mycobacterium; } \mathrm{COPD} \text {, chronic obstructive lung disease; } \\
\text { Old TB, previous tuberculosis; CRP, C-reactive protein. Data are presented as mean and standard } \\
\text { deviation, median and interquartile range, or frequency }(\%)\end{array}$} \\
\hline
\end{tabular}




\begin{tabular}{|c|c|c|c|c|}
\hline Variable & Total & Survivors & Non-survivors & $\begin{array}{l}P \\
\text { value }\end{array}$ \\
\hline CAOD & $19(10.4)$ & $17(12.0)$ & $2(5.0)$ & 0.20 \\
\hline IPF & 117 (64.3) & $87(61.3)$ & $30(75.0)$ & 0.11 \\
\hline NTM & $7(3.8)$ & $6(4.2)$ & $1(2.5)$ & 0.62 \\
\hline Old TB & $11(6.0)$ & $10(7.0)$ & $1(2.5)$ & 0.29 \\
\hline COPD & $12(6.6)$ & $11(7.7)$ & $1(2.5)$ & 0.24 \\
\hline Malignancy & $36(19.8)$ & $27(19.0)$ & $9(22.5)$ & 0.62 \\
\hline CRP (mg/L) & $\begin{array}{l}70.5(21.0- \\
140.0)\end{array}$ & $\begin{array}{l}62.4(21.0- \\
139.0)\end{array}$ & $81.5(35.0-144.5)$ & 0.22 \\
\hline $\begin{array}{l}\text { Need for mechanical } \\
\text { ventilator }\end{array}$ & 35 (19.2) & $18(12.7)$ & $17(42.5)$ & $\dot{0.001}$ \\
\hline $\begin{array}{l}\text { Use of vasopressors within } 3 \\
\text { days }\end{array}$ & $26(14.3)$ & $17(12.0)$ & $9(22.5)$ & 0.09 \\
\hline \multicolumn{5}{|c|}{$\begin{array}{l}\text { Abbreviations: ILD, interstitial lung disease; } F V C \text {, forced vital capacity; } \mathrm{FEV}_{1} \text {, forced expiratory volume } \\
\text { in } 1 \text { second; } \mathrm{DLCO} \text {, diffusing capacity of carbon monoxide; } \mathrm{P} / \mathrm{F} \text { ratio, partial pressure of oxygen in } \\
\text { arterial blood }\left(\mathrm{PaO} \mathrm{O}_{2}\right) \text { /fraction of inspired oxygen }\left(\mathrm{FiO}_{2}\right) \text { ratio; } \mathrm{GAP} \text { score system, gender }(\mathrm{G}) \text {, age }(\mathrm{A}) \text {, } \\
\text { physiology }(\mathrm{P}) ; \mathrm{AE} \text {, acute exacerbation; } \mathrm{CAOD} \text {, coronary artery occlusive disease; IPF, idiopathic } \\
\text { pulmonary fibrosis; NTM, non-tuberculous mycobacterium; COPD, chronic obstructive lung disease; } \\
\text { Old TB, previous tuberculosis; CRP, C-reactive protein. Data are presented as mean and standard } \\
\text { deviation, median and interquartile range, or frequency }(\%)\end{array}$} \\
\hline
\end{tabular}

Table 5 shows the risk factors related to mortality, which were initial P/F ratio (HR: 0.995, Cl: 0.9920.999, $P=0.006$ ), high-dose of prednisolone (HR: 0.221, Cl: 0.102-0.480, $P<0.001$ ), and need for mechanical ventilation in the first 3 hospitalization days (HR: $4.205, \mathrm{Cl}: 2.059-8.589, P<0.001)$. 
Table 5

Cox regression analysis of risk factors related to 90-day mortality in AE-ILD

\begin{tabular}{|c|c|c|c|c|c|c|}
\hline \multirow[b]{2}{*}{ Variable } & \multicolumn{3}{|c|}{ Univariate } & \multicolumn{3}{|c|}{ Multivariate } \\
\hline & $\mathrm{HR}$ & $95 \% \mathrm{Cl}$ & $\begin{array}{l}\mathrm{p}- \\
\text { value }\end{array}$ & HR & $95 \% \mathrm{Cl}$ & $\begin{array}{l}\mathrm{p} \text { - } \\
\text { value }\end{array}$ \\
\hline Age, years & 0.993 & $\begin{array}{l}0.968- \\
1.019\end{array}$ & 0.603 & 0.989 & $\begin{array}{l}0.957- \\
1.009\end{array}$ & 0.200 \\
\hline Sex, male & 1.228 & $\begin{array}{l}0.624- \\
2.415\end{array}$ & 0.552 & 0.777 & $\begin{array}{l}0.377- \\
1.599\end{array}$ & 0.493 \\
\hline Initial $P / F$ ratio & 0.998 & $\begin{array}{l}0.998- \\
1.001\end{array}$ & 0.241 & 0.995 & $\begin{array}{l}0.992- \\
0.999\end{array}$ & 0.006 \\
\hline FVC (\%), predicted & 0.994 & $\begin{array}{l}0.975- \\
1.014\end{array}$ & 0.540 & & & \\
\hline DLco (\%), predicted & 0.976 & $\begin{array}{l}0.952- \\
1.001\end{array}$ & 0.059 & & & \\
\hline Prednisolone $>1$ mg/kg & 0.380 & $\begin{array}{l}0.193- \\
0.747\end{array}$ & 0.005 & 0.221 & $\begin{array}{l}0.102- \\
0.480\end{array}$ & $\begin{array}{l}< \\
0.001\end{array}$ \\
\hline $\begin{array}{l}\text { Use of vasopressors within } 3 \\
\text { days }\end{array}$ & 1.852 & $\begin{array}{l}0.881- \\
3.890\end{array}$ & 0.104 & 1.451 & $\begin{array}{l}0.630- \\
3.340\end{array}$ & 0.382 \\
\hline Need for mechanical ventilator & 3.877 & $\begin{array}{l}2.068- \\
7.267\end{array}$ & $\dot{0}_{0.001}$ & 4.205 & $\begin{array}{l}2.059- \\
8.589\end{array}$ & $\begin{array}{l}<.001 \\
0.0\end{array}$ \\
\hline \multicolumn{7}{|c|}{$\begin{array}{l}\text { Abbreviations: AE-ILD, acute exacerbation of interstitial lung disease; FVC, forced vital capacity; DLco, } \\
\text { diffusing capacity of carbon monoxide; P/F ratio, partial pressure of oxygen in arterial blood } \\
\left(\mathrm{PaO}_{2}\right) / \text { fraction of inspired oxygen }\left(\mathrm{FiO}_{2}\right) \text { ratio; } \mathrm{HR} \text {, hazard ratio }\end{array}$} \\
\hline
\end{tabular}

Kaplan-Meier estimates of 90-day mortality according to corticosteroid dose are shown in Fig. 1.

The survival rate was significantly higher when the prednisolone dose was higher than $1 \mathrm{mg} / \mathrm{kg}$ in the total sample of AE-ILD patients (Fig. 1A, log-rank test, $P=0.003$ ). The same results were observed in the non-IPF ILD group (Fig. 1C, log-rank test, $P=0.001$ ). In the IPF group, however, the 90-day mortality analysis was not statistically significant (Fig. 1B, log-rank test, $P=0.142$ ).

e-Figure 1 shows that survival rates of the triggered and non-triggered AE-ILD groups according to corticosteroid dose were not significantly different. The main cause of death was respiratory failure caused by AE-ILD $(n=24)$, followed by pneumonia $(n=10)$ and combined lung cancer progression $(n=6)$.

\section{Discussion}

This retrospective study showed that high doses of corticosteroids are beneficial in most cases of AE-ILD, especially in cases of AE-non-IPF ILD, but not in cases of AE-IPF. Survival improved when doses of 
prednisolone higher than $1 \mathrm{mg} / \mathrm{kg}$ were administered.

The immediate outcome of $A E$ is very poor; the median survival is 2.2 months from onset, and half of the patients die during hospitalization ${ }^{4,6}$. Furthermore, about $50 \%$ of patients need admission to an intensive care unit ${ }^{4}$. However, the optimal treatment for AE-IPF remains undetermined. A recent retrospective study showed that pirfenidone combined with corticosteroids and recombinant human thrombomodulin may improve survival in patients with AE-IPF (55\% in patients with pirfenidone vs $34 \%$ in control group, $p=$ $0.042)^{13}$. Most experts ${ }^{14}$ administer systemic corticosteroids with or without immunosuppressants, but the various drug regimens used in these two treatment approaches have not been evaluated in randomized controlled trials. Hence, the recommendation of corticosteroid treatment is based on lowquality evidence ${ }^{12}$. However, most patients are treated with high-dose immunosuppression therapy, typically with pulses of 500-1000 mg of methylprednisolone daily for 3 days ${ }^{3,6}$. The 2018 Japanese IPF treatment guidelines suggest that patients with AE-IPF should be treated with corticosteroids, including pulse therapy ${ }^{15}$. This is contradicted by the results of Mengshu et al., ${ }^{16}$ who reported that high doses of corticosteroids are not beneficial for AE-ILD patients, and that the clinical outcomes of patients with AEIPF mainly depend on the underlying clinical condition and the extent of lung injury from the AE. Thus, there remains a lack of consensus regarding proper treatment of AE-ILD.

Feghali-Bostwick et al. ${ }^{17}$ showed that patients with IPF frequently have autoantibodies and self-reactive CD4 $\mathrm{T}$ cells, thus fulfilling the diagnostic criteria for an autoimmune disease ${ }^{18}$. Moreover, there is a component of inflammation in AE-IPF ${ }^{19}$. Therefore, some patients respond to corticosteroids ${ }^{20}$. However, a recent study from 2020 showed no evidence that corticosteroids improve the outcome of patients with AE-IPF admitted to the hospital; furthermore, the results indicated that corticosteroid use following an exacerbation may contribute to reduced overall survival ${ }^{21}$. Our study showed the same results in AE-IPF cases.

The 90-day mortality rate in this study was relatively low $(25.6 \%$ in the IPF group and $15.4 \%$ in the non-IPF ILD group) compared to other studies (mortality rate: $50-80 \%)^{10,22}$. The patients in our study were mainly diagnosed with mild ARDS (median P/F ratio: 223.4), and pirfenidone was administered in $41.6 \%(n=54)$ of IPF patients before AE. A higher survival rate has been reported for patients with AE-IPF who were administered pirfenidone (55\%) compared to those not administered pirfenidone $(34 \% ; p=0.042)^{13}$. Recent developments in ARDS and sepsis management, as well as the use of high corticosteroid doses, may contribute to reduced mortality rates in this patient group.

Non-IPF ILD is also associated with autoimmunity, and thus has potential to respond well to corticosteroid treatment. According to the abovementioned mechanism of ILD, it could be speculated that corticosteroids would be effective in cases of AE-non-IPF ILD, but not in cases of AE-IPF.

AE-ILD can be precipitated by a variety of factors ${ }^{1}$. Viral infections, air pollution, aspiration, transfusions, drugs, or surgery, all leading to acceleration of the fibro-proliferative response, have been postulated as 
triggers of AE-ILD. However, the specific factors that cause some patients with ILD and not others to develop $A E$ are unknown ${ }^{3,23}$. Although an infectious trigger could explain why some patients develop $A E$ and others do not, no firm associations between bacterial or viral infections (including Epstein-Barr virus, cytomegalovirus, and human herpesvirus 8 ) and AE have been identified ${ }^{6}$. Our study identified 50 cases of AE-ILD triggered by bacterial, fungal, or viral infections. These patients had a worse survival outcome (90-day mortality of $22 \%$ compared to $15.8 \%$ in the non-triggered $A E$ cases), although the difference was not statistically significant. However, triggered AE-ILD cases showed a more severe clinical course, including lower P/F ratios and higher lactate levels. Depending on the severity of the disease, fluid resuscitation, antibiotic use, initial ventilator care, sepsis management, and corticosteroid therapy could be needed.

Huie et al. suggested that patients with IPF have a lower survival rate after an acute respiratory decline as compared to patients with non-IPF fibrotic disease ${ }^{24}$. Pathophysiologically, AE-ILD resembles an acute lung injury, which presents histopathologically as diffuse alveolar damage in most cases ${ }^{25}$. A number of factors (including low baseline $F V C$ and $\mathrm{DL}_{\mathrm{CO}}$, extensive $\mathrm{CT}$ abnormalities and the involvement pattern, low oxygenation, and high bronchoalveolar lavage fluid neutrophil and lymphocyte percentages at the time of $A E$ ) have been reported as associated with survival of patients with AE-IPF $3,26,27$. However, this study could not demonstrate the significance of the radiologic and cellular pattern of bronchoalveolar lavage fluid because of a small sample size.

Patients who required mechanical ventilation from the beginning had a significantly higher mortality rate, possibly due to individual differences in the response to oxygen and steroid therapy in the setting of $A E$. Further studies are needed to assess individual differences in the response to oxygen and steroid therapy.

The present study had several limitations. First, this study analyzed data of a single tertiary center. Second, although we tried to obtain complete data by reviewing medical records, not all patients underwent a complete examination (e.g., missing microbiologic studies) at the initial visit to the ED. Third, we could not analyze long-term complications of corticosteroid therapy; therefore, we could not identify whether their use led to adverse outcomes such as opportunistic infections.

Despite the limitations, this study provides useful evidence for proper initial management and for decision-making regarding corticosteroid use in patients with AE-non-IPF ILD. Determining the corticosteroid dose and the administration modality (pulse therapy or routine high-dose steroids) is always difficult because of the potential side effects of corticosteroids. A larger-sample prospective study of patients with AE-ILD is, therefore, needed to address these limitations.

\section{Methods}

\section{Study design and sample}


This study was conducted retrospectively in a tertiary care hospital in South Korea. We reviewed medical records and all chest computed tomography (CT) scans of patients who were diagnosed with ILD and presented to the ED with symptoms of dyspnea at the Severance Hospital between January 2016 and December 2018. A total of 534 patients were initially screened and 330 were excluded for the following reasons: (1) fluid overload, (2) congestive heart failure, (3) pulmonary embolism, (4) dyspnea unrelated to respiratory disease, and (5) worsening symptoms for more than 1 month. Finally, 205 patients with AEILD were enrolled. A further 23 cases were excluded because of insufficient data, including lack of pulmonary function test results within 6 months before the ED visit and unavailable baseline arterial blood gas values, resulting in 182 selected patients. In June 2019, all subjects were reevaluated by multidisciplinary discussion using patient history, physical examination, laboratory results, chest highresolution $\mathrm{CT}$ (HRCT), and histopathological findings. The final diagnoses were categorized as IPF and non-IPF ILD; the latter diagnosis included connective tissue disease-associated ILD, idiopathic nonspecific interstitial pneumonia, cryptogenic organizing pneumonia, sarcoidosis, hypersensitivity pneumonitis, and other conditions (toxic humidifier sterilizers-induced ILD and amiodarone-induced ILD). Among the included patients, 117 had IPF and 65 had non-IPF ILD (Fig. 2).

The following clinical and laboratory data were collected from medical records: age, sex, smoking history, pulmonary function test results within 6 months before presenting to the ED, underlying diseases, ratio of initial partial pressure of oxygen in arterial blood $\left(\mathrm{PaO}_{2}\right)$ to fraction of inspired oxygen ( $\mathrm{FiO}_{2} ; \mathrm{P} / \mathrm{F}$ ratio), gender-age-physiology (GAP) index score, prednisolone dose, serum concentrations of C-reactive protein (CRP) and lactate, and date of death. An ever smoker was defined as a person who had smoked at least 100 cigarettes or cigars during the course of their life.

The research protocol was approved by the Institutional Review Board of Severance Hospital, South Korea (IRB No. 4-2020-0398). The study design was approved by the appropriate ethics review boards. The requirement to obtain informed patient consent was waived by the IRB.

\section{Definitions}

In this study, AE-IPF was defined as a clinically significant respiratory deterioration developing typically within less than 1 month, accompanied by new radiologic abnormalities on HRCT (e.g., diffuse bilateral ground-glass opacification), and with an absence of other obvious clinical causes such as fluid overload, congestive heart failure, or pulmonary embolism. This is in accordance with the official American Thoracic Society/European Respiratory Society/Japanese Respiratory Society/Latin American Thoracic Society IPF guidelines ${ }^{10}$.

This new definition promotes discrimination between a triggered form of AE-IPF (e.g., infectious, postprocedural/postoperative, or toxic) and an idiopathic form of $A E-I P F$, in which no trigger is identified ${ }^{5,10}$. Regarding other AE-ILDs, it is more challenging to establish the specific diagnoses. The most important element for diagnosing AE-ILDs is the HRCT, which must be performed when patients are 
clinically stable. The typical HRCT findings in AE-ILD are newly developed bilateral alveolar infiltrates and ground-glass opacification with or without consolidation ${ }^{6,12}$. Since there is no definition of AE in non-IPF ILD cases, the definition of AE-IPF was applied.

The GAP score was calculated for all patients (IPF and non-IPF) based on sex (0-1 points), age ( $0-2$ points), FVC (0-2 points), and $\mathrm{DL}_{\mathrm{CO}}$ (0-3 points), and classified into stages I ( $0-3$ points), II (4-5 points), or III (6-8 points), as previously described ${ }^{28}$. Outcome measures were determined based on the medical record review. The primary outcome measure was 90-day mortality.

\section{Treatment Protocol And Steroid Dosage}

For patients diagnosed with AE-ILD in the ED, blood tests (including serum inflammatory markers and routine chemistry), microbiologic cultures, and chest CT scans were initially performed. Bronchoscopy with bronchoalveolar lavage, which is an invasive diagnostic procedure, was not routinely performed initially due to poor patient tolerance.

In our institution, the main treatment for AE-ILD is the administration of corticosteroids together with effective antibiotics. Additionally, we aim for symptom palliation with supplemental oxygen therapy, mechanical ventilation when needed, acute respiratory distress syndrome (ARDS) therapy, and shock management.

Corticosteroids are usually administered at doses ranging from $0.5 \mathrm{mg} / \mathrm{kg}$ to $2 \mathrm{mg} / \mathrm{kg}$, depending on the clinical situation. Steroid pulse therapy was not usually applied except for cases of vasculitis or dermatomyositis-associated rapid progressive ILD.

\section{Statistical analysis}

Baseline characteristics, including demographics, baseline pulmonary function, respiratory parameters, hematologic data, serum CRP and lactate, and survival, were compared between patients with IPF and patients with non-IPF ILD according to corticosteroid dose. Categorical variables were compared using Pearson's chi-square test and are reported as numbers and percentages. Continuous variables were compared using logistic regression models. Continuous variables with normal distributions are reported as mean and standard deviation, while variables with non-normal distributions are reported as median and interquartile range (IQR, 25th to 75th percentiles). We further investigated the relationship between clinical parameters and mortality using Cox proportional hazard models with stepwise selection of variables found to be significant in the univariate regression analysis.

Cumulative time-to-event distributions (survival) were estimated using the Kaplan-Meier method. Statistical significance was determined by the log-rank test. In all cases, $P$ values $<0.05$ were considered statistically significant. All statistical analyses were performed with IBM SPSS Statistics (version 25.0, Chicago, IL, USA). 


\section{Declarations}

Guarantor: Moo Suk Park

\section{Author Contributions:}

Study Conception and Design, HJ Jang and MS Park; Acquisition of Data, HJ Jang, SH Yong, J Chang, EY Kim, SH Lee, and YS Kim; Analysis and Interpretation of Data, HJ Jang, EY Kim, SH Yong, SY Kim, and MS Park; Drafting of Manuscript, HJ Jang, AY Lim, SY Kim, SH Lee, and MS Park; Technical Support and Consulting, SH Lee, KS Chung, SH Lee, EY Kim, JY Jung, and YA Kang. All authors have read and approved the final manuscript.

Financial/nonfinancial disclosures: None declared.

Role of the sponsors: This research was not sponsored.

Other contributions: None to declare.

Summary conflict of interest statement: All authors declare no conflict of interest.

Funding: This research received no external funding.

Notation of prior abstract publication/presentation: The abstract of this study has not been published/presented before.

\section{References}

1. Amundson, W. H. et al. Acute exacerbation of interstitial lung disease after procedures. Respiratory Medicine 150, 30-37, doi:https://doi.org/10.1016/j.rmed.2019.02.012 (2019).

2. Kannapiran, M. \& Kim, H. Diagnostic evaluation of the patient with interstitial lung disease. Clinical Pulmonary Medicine 19, 71-77 (2012).

3. Kim, D. S. et al. Acute exacerbation of idiopathic pulmonary fibrosis: frequency and clinical features. European Respiratory Journal 27, 143, doi:10.1183/09031936.06.00114004 (2006).

4. Song, J. W., Hong, S.-B., Lim, C.-M., Koh, Y. \& Kim, D. S. Acute exacerbation of idiopathic pulmonary fibrosis: incidence, risk factors and outcome. European Respiratory Journal 37, 356-363 (2011).

5. Kim, D. S. Acute exacerbation of idiopathic pulmonary fibrosis. Reference Module in Biomedical Sciences (2019).

6. Hyzy, R., Huang, S., Myers, J., Flaherty, K. \& Martinez, F. Acute exacerbation of idiopathic pulmonary fibrosis. Chest 132, 1652-1658 (2007).

7. King Jr, T. E., Pardo, A. \& Selman, M. Idiopathic pulmonary fibrosis. The Lancet 378, 1949-1961 (2011). 
8. Toyoda, Y. et al. Clinical features and outcome of acute exacerbation of interstitial pneumonia associated with connective tissue disease. The Journal of Medical Investigation 63, 294-299 (2016).

9. Leuschner, G. \& Behr, J. Acute Exacerbation in Interstitial Lung Disease. Front Med (Lausanne) 4, 176-176, doi:10.3389/fmed.2017.00176 (2017).

10. Collard, H. R. et al. Acute exacerbation of idiopathic pulmonary fibrosis. An international working group report. American journal of respiratory and critical care medicine 194, 265-275 (2016).

11. Shintani, Y. et al. Predictive factors for postoperative acute exacerbation of interstitial pneumonia combined with lung cancer. General thoracic and cardiovascular surgery 58, 182-185 (2010).

12. Raghu, G. et al. An official ATS/ERS/JRS/ALAT statement: idiopathic pulmonary fibrosis: evidencebased guidelines for diagnosis and management. Am J Respir Crit Care Med 183, 788-824, doi:10.1164/rccm.2009-040GL (2011).

13. Furuya, K. et al. Pirfenidone for acute exacerbation of idiopathic pulmonary fibrosis: A retrospective study. Respiratory Medicine 126, 93-99, doi:https://doi.org/10.1016/j.rmed.2017.03.026 (2017).

14. Biondini, D. et al. Acute exacerbations of idiopathic pulmonary fibrosis (AE-IPF): an overview of current and future therapeutic strategies. Expert Review of Respiratory Medicine 14, 405-414, doi:10.1080/17476348.2020.1724096 (2020).

15. Homma, S. et al. Japanese guideline for the treatment of idiopathic pulmonary fibrosis. Respir Investig 56, 268-291, doi:10.1016/j.resinv.2018.03.003 (2018).

16. Cao, M. et al. Acute exacerbations of fibrosing interstitial lung disease associated with connective tissue diseases: a population-based study. BMC Pulmonary Medicine 19, 215, doi:10.1186/s12890019-0960-1 (2019).

17. Feghali-Bostwick, C. A. et al. Cellular and Humoral Autoreactivity in Idiopathic Pulmonary Fibrosis. The Journal of Immunology 179, 2592-2599, doi:10.4049/jimmunol.179.4.2592 (2007).

18. Ermann, J. \& Fathman, C. G. Autoimmune diseases: genes, bugs and failed regulation. Nature immunology 2, 759-761 (2001).

19. American Thoracic Society. Idiopathic pulmonary fibrosis: diagnosis and treatment. International consensus statement. American Thoracic Society (ATS), and the European Respiratory Society (ERS). Am J Respir Crit Care Med 161, 646-664, doi:10.1164/ajrccm.161.2.ats3-00 (2000).

20. Arai, T. et al. High-dose prednisolone after intravenous methylprednisolone improves prognosis of acute exacerbation in idiopathic interstitial pneumonias. Respirology 22, 1363-1370, doi:10.1111/resp.13065 (2017).

21. Farrand, E., Vittinghoff, E., Ley, B., Butte, A. J. \& Collard, H. R. Corticosteroid use is not associated with improved outcomes in acute exacerbation of IPF. Respirology 25, 629-635, doi:10.1111/resp.13753 (2020).

22. Perlman, D. M., Bhargava, M., Kim, H. J., Ritter, J. H. \& Tomic, R. Acute Exacerbation of Idiopathic Pulmonary Fibrosis. Clinical Pulmonary Medicine 21, 262-268, doi:10.1097/cpm.0000000000000068 (2014). 
23. Kim, H. J., Perlman, D. \& Tomic, R. Natural history of idiopathic pulmonary fibrosis. Respiratory medicine 109, 661-670 (2015).

24. Huie, T. J. et al. A detailed evaluation of acute respiratory decline in patients with fibrotic lung disease: aetiology and outcomes. Respirology 15, 909-917 (2010).

25. Oda, K. et al. Autopsy analyses in acute exacerbation of idiopathic pulmonary fibrosis. Respiratory Research 15, 1-9 (2014).

26. Sakamoto, S. et al. Cyclosporin A in the treatment of acute exacerbation of idiopathic pulmonary fibrosis. Internal Medicine 49, 109-115 (2010).

27. Kataoka, K. et al. Recombinant human thrombomodulin in acute exacerbation of idiopathic pulmonary fibrosis. Chest 148, 436-443 (2015).

28. Ley, B. et al. A Multidimensional Index and Staging System for Idiopathic Pulmonary Fibrosis. Annals of Internal Medicine 156, 684-691, doi:10.7326/0003-4819-156-10-201205150-00004 (2012).

\section{Figures}


A.

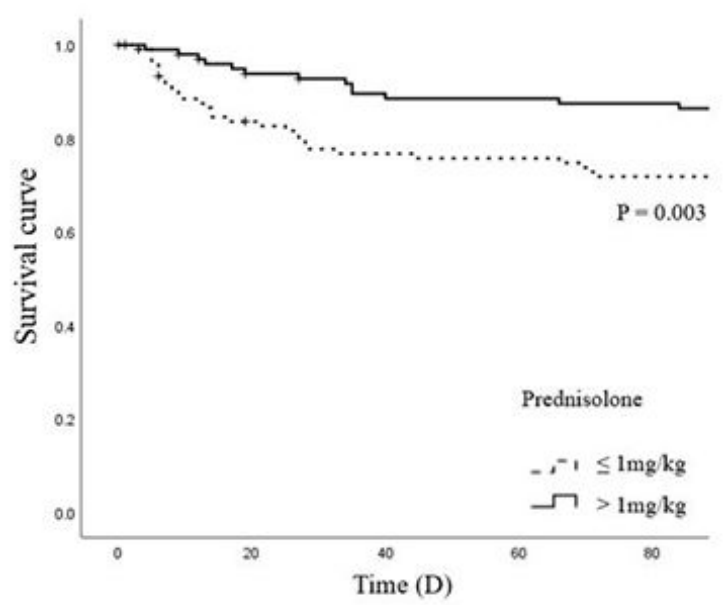

B.

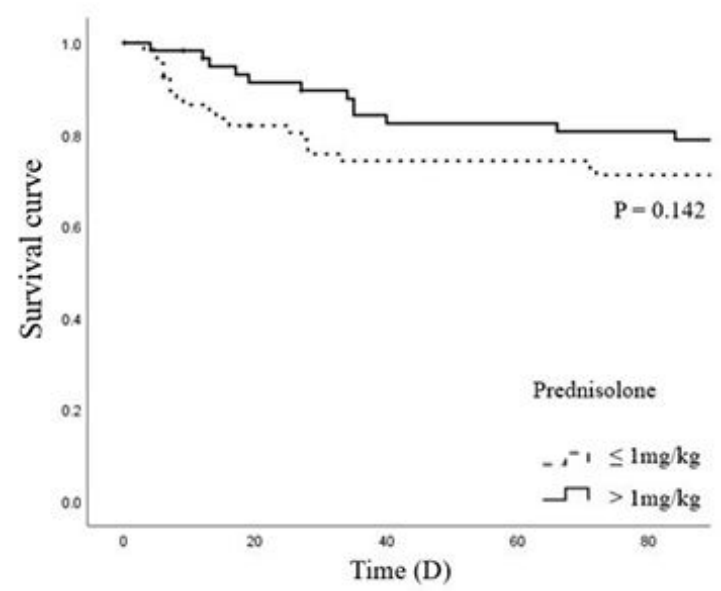

C.

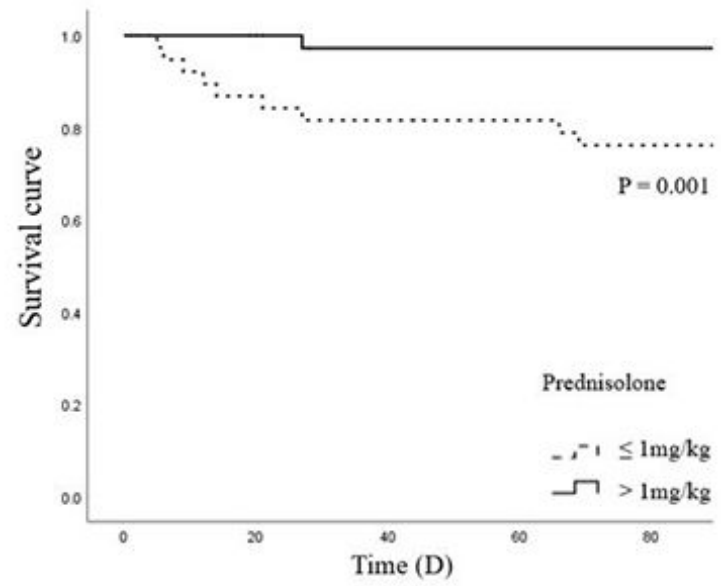

\section{Figure 1}

Kaplan-Meier survival curves according to corticosteroid use in A) total patients; B) patients with IPF; C) patients with non-IPF ILD 


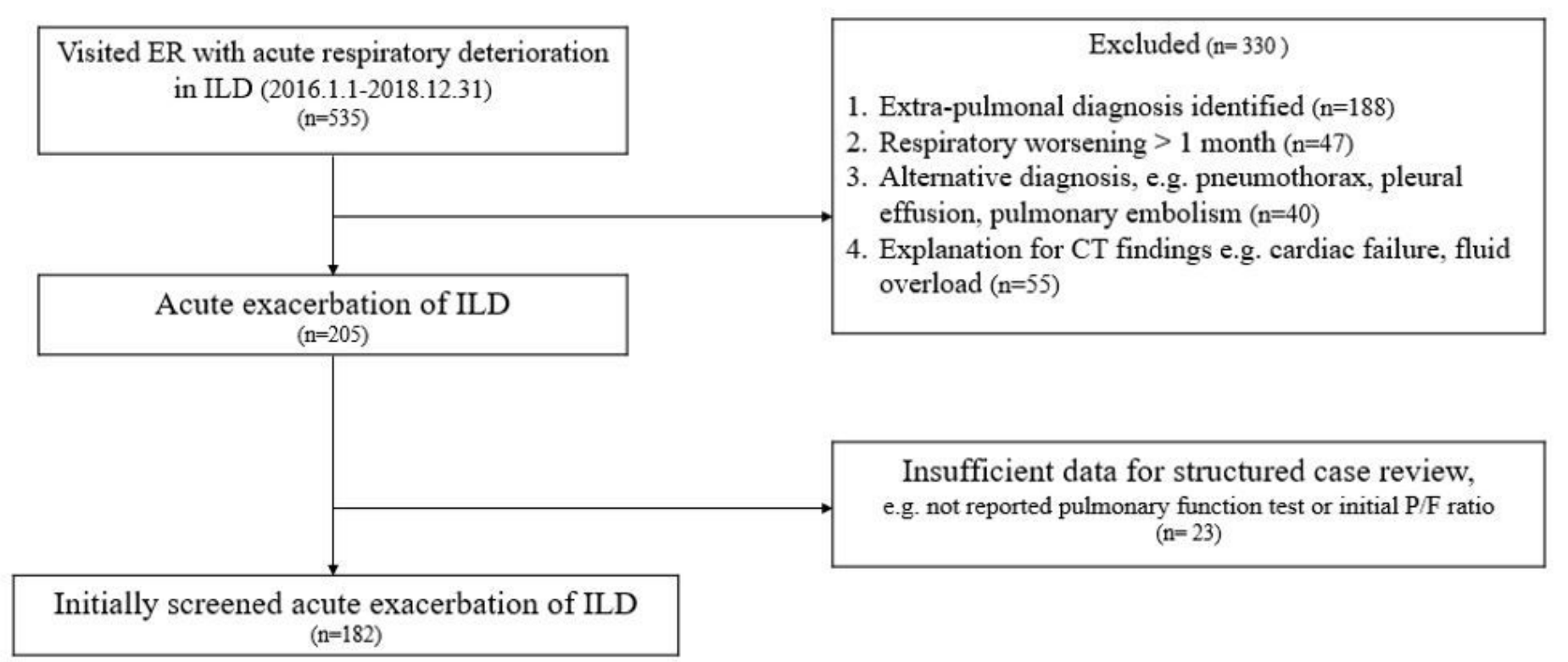

\section{Figure 2}

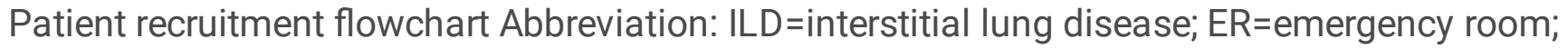
CT=computed tomography

\section{Supplementary Files}

This is a list of supplementary files associated with this preprint. Click to download.

- supplementalmaterial.docx 